


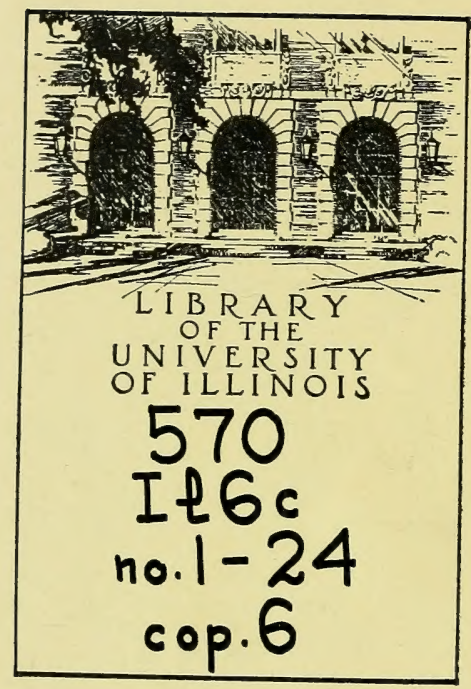

NATURAL HISTORY
SURVEY 
Digitized by the Internet Archive in 2011 with funding from

University of Illinois Urbana-Champaign

http://www.archive.org/details/careoftrees24sawy 





\section{If 60}

no.24

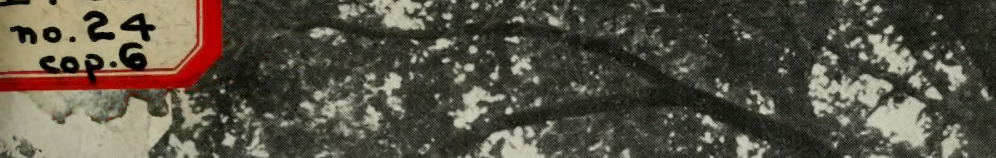

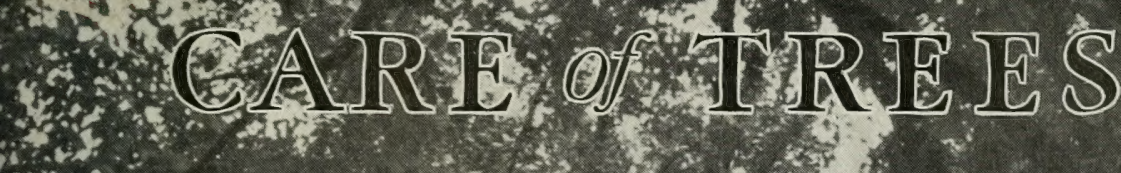

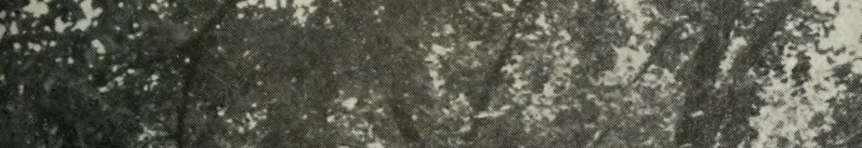
$+x^{x}+x^{5}=$ $\frac{1}{2}+2+2$ (2)

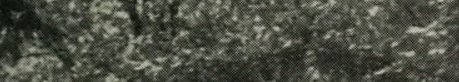

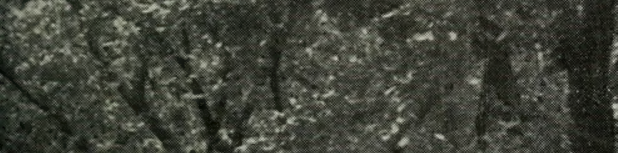

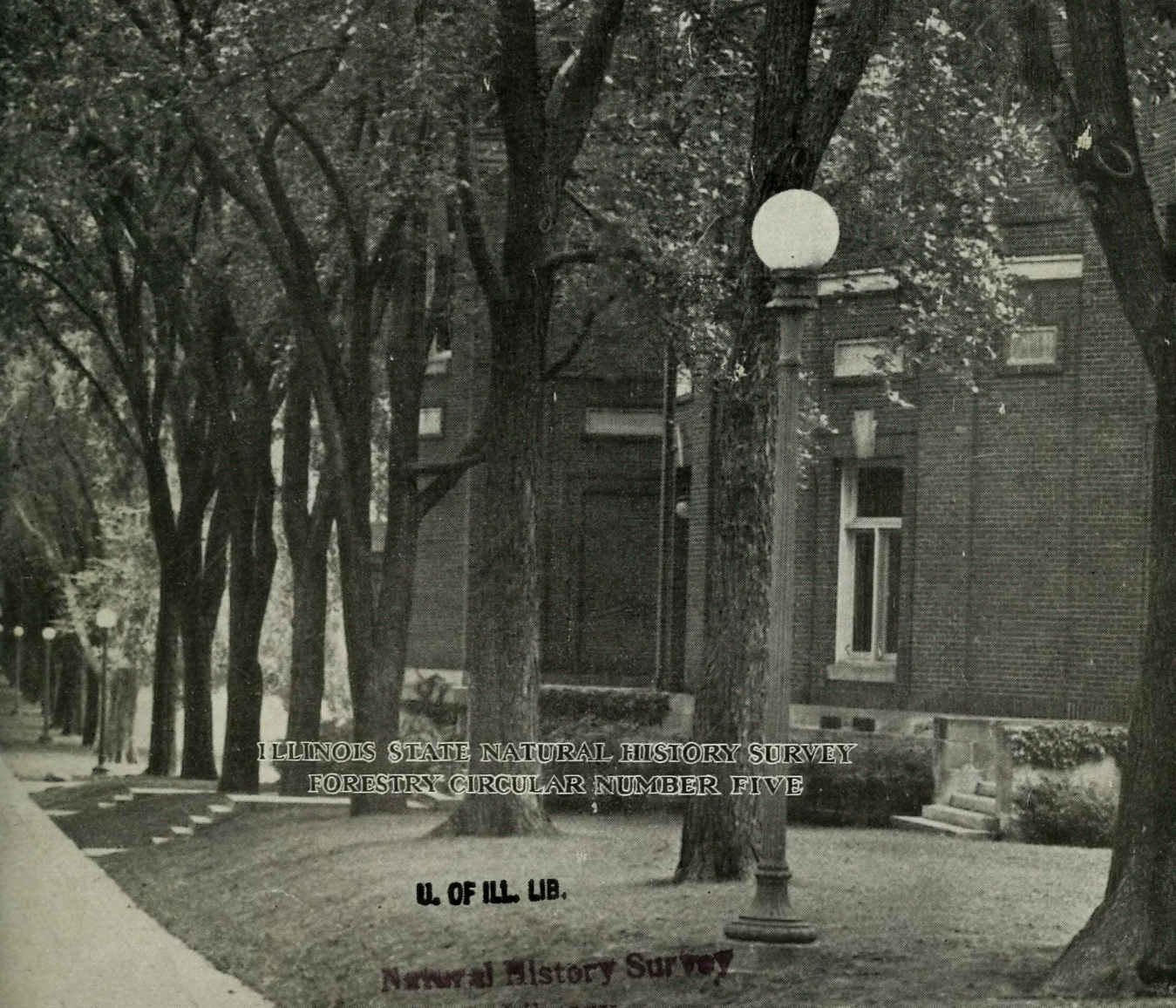



STATE OF ILLINOIS

DEPARTMENT OF REGISTRATION AND EDUCATION

DIVISION OF THE

NATURAL HISTORY SURVEY

THEODORE H. FRISON, Chief

\section{Care of Trees}

L. E. SAWYER, EXTENSION FORESTER 


\section{STATE OF ILLINOIS DEPARTMENT OF REGISTRATION AND EDUCATION \\ M. F. WALSH, DIRECTOR}

BOARD OF NATURAL RESOURCES AND CONSERVATION

M. F. WALSH, Chamman

William Trelease, Biology Henry C. Cowles, forestry EDSON S. BASTIN, GEOLOGY WILIIAM A. Noyes, CHEMISTRY
JoHN W. ALVord, ENGINEERING

Charles M. Thompson, representing THE PRESIDENT OF THE UNIVERSITY OF 'ILLINOIS

\section{STATE NATURAL HISTORY SURVEY DIVISION}

THEODORE H. Frison, CHIEF

Carroll Chouinard, editor

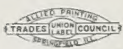

Jeffersons Printing \& Stationery Co. Springfield, Illinois

1932

$(69715-3 \mathrm{M})$ 


\section{CARE OF TREES}

\section{E. SAWYER, EXTENSION FORESTER}

Under the conditions imposed on town and eity trees they will not do well unless given proper attention. Trees growing under natural conditions will be so close together that they will develop a long clear trunk and a comparatively small crown. Their shade will be so dense that no grass will be found under them and the accumulation of decaying leaves, branches and other litter will be conserving moisture and adding plant food to the soil.

How different are the conditions under which our city trees are expected to thrive. Such trees are widely separated and have large bushy crowns, a heavy sod usually grows up to their very trunks and all of the litter is raked away from under them. Evaporation from the erowns requires large supplies of moisture and plant food yet the rain that falls is quickly carried away by storm sewers and the heavy sod is using food that the trees require. Under these conditions a tree needs to have three services performed for it, namely watering, feeding and trimming.

\section{WATERING}

The leaf mulch in a stand of timber absorbs moisture as does a sponge and allows it to soak into the ground gradually. Watering on the surface is little if any benefit to the tree as the majority of the feeding roots are from 12 to 24 inches below the surface and the amount of water required to penetrate to that depth is seldom if ever applied. The most thorough, and in the long run most economical, way of watering shade trees is by the use of tiles. Set in the

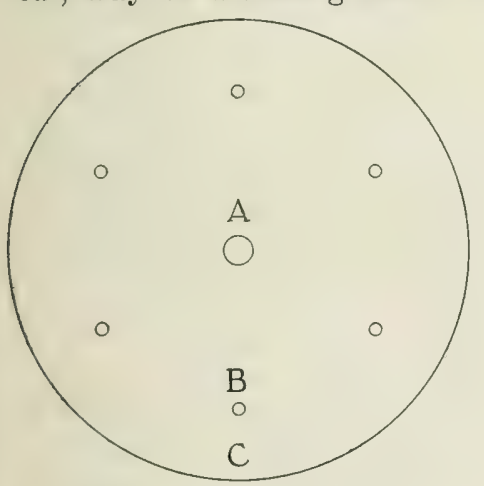

Fig. 1. Placement of Tiles for WATERING AND FeEding. The tree is represented by circle $A$. The tiles are at $B$, out from the tree two-thirds to three-quarters of the branch spread, or the distance from A to C.

them, two or three times a week, it will be found that the trees can ground on end, two-thirds to three-fourths the distance of the branch spread out from the tree, a joint of four-inch tile 12 or 24 inches long. The number of tiles to a tree will be governed by its size, one or two being enough for small trees, but four or more are required for large ones and with very large trees it would be advisable to set tiles at 10 to 15 foot intervals around the tree in a circle the radius of which is twothirds the average branch spread of the trees. The tops of these tiles should be flush with the surface of the ground so they will not interfere with lawn mowers. If in periods of dry weather the tiles around a tree are given all the water readily absorbed from 
be watered more economically, and that the water will be applied down where it is available to the feeding roots.

\section{FERTILIZATION}

Presence of a heavy sod under trees and lack of decaying leaf mould makes feeding of trees necessary if they are to thrive. Grass consumes large quantities of food materials vital to the tree and in the absence of decaying matter on the ground no plant food is being put back into the soil. The chief chemical elements removed from the soil by both grass and trees are potash, phosphorus and nitrogen. Soil is usually most deficient in nitrogen, the element for lack of which trees suffer most. These elements may be returned to the soil in several ways, first, by mulching the area under the tree as far out as the branches spread with two or three inches of well rotted stable manure. This should be done in the fall and the mulch worked three or four inches into the soil in the early spring.

Secondly, spread one to ten pounds of sodium nitrate, calcium nitrate or any commercial fertilizer rich in potash, phosphorus and nitrogen under the tree several times during the growing season, the amount used depending entirely upon the size of the tree. Spread this material only after a heavy rain when the ground is well saturated, but wait long enough for the grass to become thoroughly dry, otherwise it will be severely burned. The ideal time for this application is between rains for if the ground gets a good soaking a day or two after the application, the fertilizer will seep down to where it will be readily available. If there has been no rain, it is an excellent plan to give the ground a good soaking with a hose two or three days after the fertilizer has been applied.

Third, nitrogen and other plant foods may easily be furnished trees equipped with tile for watering purposes by dissolving nitrate of soda in the proportions of one pound of nitrate to 50 gallons of water and applying from one to 50 gallons of the mixture to each tree, depending on its size, at two or three week intervals from the time growth starts in the spring until about the middle of July. After this date fertilizer should not be applied, for later growth will not have time to harden before the frosts and will be killed, making the tree more susceptible to disease and insect attacks.

\section{TRIMMING}

Only too often the proper trimming of our trees is neglected until it is found that decay, having entered through dead and decayed branches which should have been removed or treated years ago, has left nothing but a shell and the tree is not worth the cost of the extensive work necessary to remedy its condition. Trees, like people, should be given an examination at regular intervals of one to three years. All dead branches should be removed and the wounds made by previous removal of other branches repainted.

Evil practices exist in trimming trees as they do in every other occupation, the most glaring being the apparently state-wide practice of topping trees. Magnificent trees of practically every kind are deformed by local talent tree trimmers. These local trimmers, 


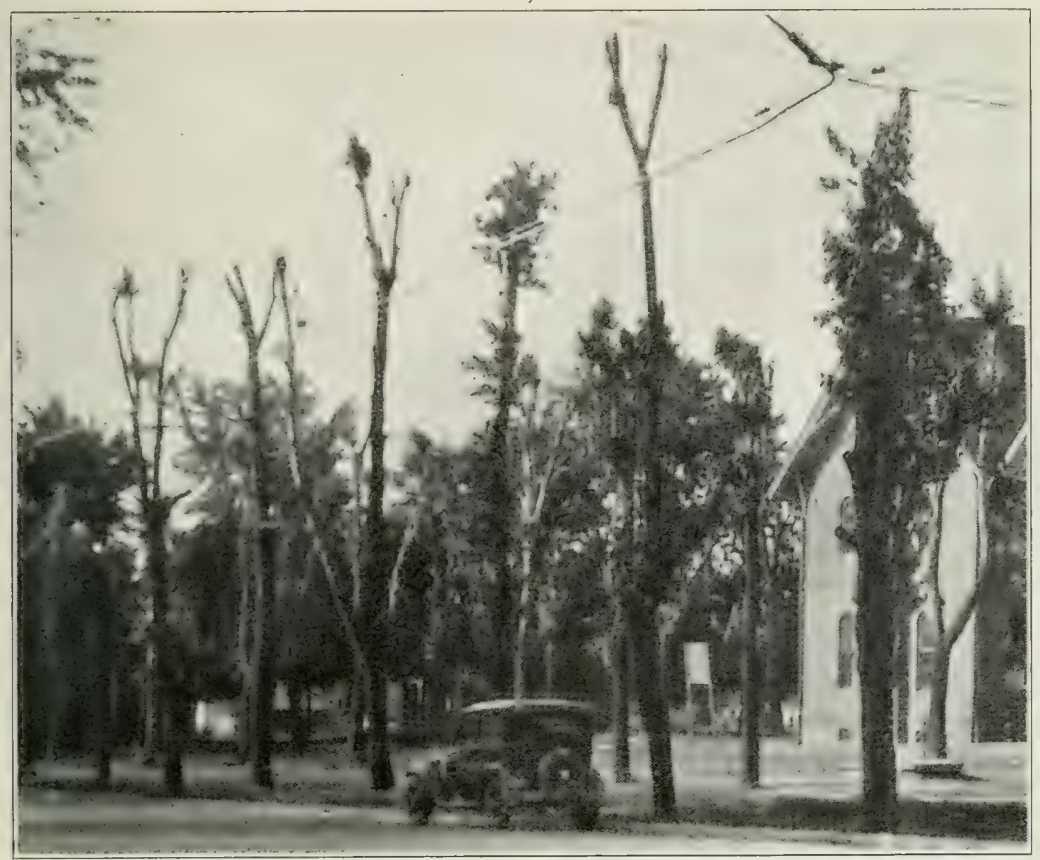

Fig. 2. Trees Ruined by Topping. These trees about the grade school at Carmi, Illinois, were topped during the summer of 1929 . Fourteen of the trees have died, and many more will not leaf out next spring. The bark on the southwest. side of nearly two-thirds of the living trees has blistered because of exposure to the direct rays of the sun.

either through ignorance or because they can not or will not learn by observation, proceed to cut the entire tops out of large trees, leaving nothing but the trumk with large stubs. Many trees so abused are killed outright, while the mutilated survivors produce a vigorous growth of suckers and in a few years have a small, compact crown composed entirely of weak shoots. The large stubs left by the trimmers, or butchers as they should be called, will begin to decay and in the course of time all that is left of the branch will be a shell supporting a growth of large shoots. The first heavy wind or sleet storm will complete the ruin by breaking off many if not all of these newly formed branches and many of the stubs. If tree tops are too large and heavy they should be thinned and not topped as they now all too frequently are.

Entire branches should be removed from the main limbs to relieve the weight on them and if the tree is too tall the ends of the branches should be cut back to a diameter of one to two inches and the ends painted with a good preservative.

Trimming may be done at any time of the year except when the sap is flowing in the spring, the best time being during the late summer, fall and early winter. Late summer or autumn is preferred since before the leaves fall it is much easier to determine which limbs are unhealthy. 
Tools for Trimming-Tools to be used in tree trimming are not highly specialized or very expensive. Many types of saws are used, varying from the ordinary hand saw to the meat saw type. All of the various kinds have their merits, personal preferences playing a big part in their selection. A doubly toothed saw, slightly curved, is an excellent one for all-round work. This saw has teeth on the concave side that eut only on the pull stroke, while the teeth on the back or convex side are of the type ordinarily found on hand saws. The end of the saw is about one and one-half inches wide, and may be easily inserted into narrow crotches. The teeth cutting on the pull stroke enable the user to cut equally well directly overhead or under a limb, while with the ordinary hand saw it is easier to work standing a little above the limb to be cut. One hand saw, another fastened to the end of a pole 12 or 14 feet long, two 50-foot lengths of three-eighths inch rope, a brush and paint bucket, and if much work is to be done a lineman's safety belt and strap, are all the equipment necessary.

The 50-foot ropes will be very handy in pulling equipment up into the trees, climbing up to begin work, and in letting one's self down after the work is completed. The brush and paint bucket are indispensible as every cut over a half inch in diameter should be treated. A safety belt is a very important part of the equipment as with it one is free to use both hands at his work without danger of falling. The pole saw will be useful in removing small limbs and the ends of others that will not support the weight of the trimmer.

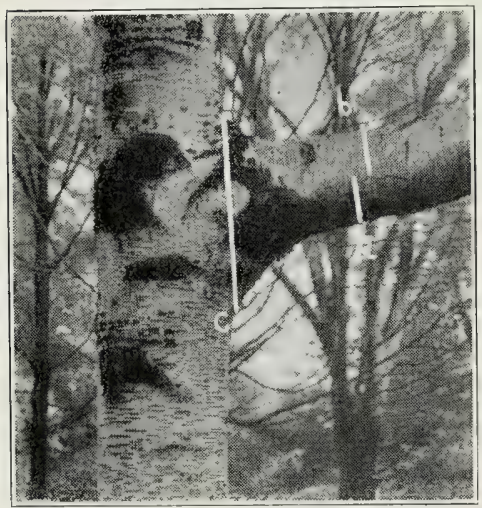

Fig. 3. How to Cut Away a LARGE LIMB. Make cuts a, b and c in order.

One piece of equipment, standard with all line and telephone crews, should not be allowed in any tree. This is the spur or climber used by linemen in pole work and which they ordinarily use when trimming trees. The use of climbers in a tree is a practice to be stopped, for every insertion of the spur leaves a wound to pocket moisture and foster the entrance of disease.

Many trees are left in very poor condition after trimming. As a majority of the cuts are often improperly made, the trees are left full of stubs that will never grow over but eventually rot back into the main trunk. Limbs the weight of which can not be controlled by the hand not occupied in cutting should be removed by three cuts as shown in fig. 3 instead of by one or two cuts as is usually the case. If large heavy limbs are removed with only one cut, they will split down the side of the tree before being completely sawed through, making a wound that will require additional treatment and take many years to heal. 


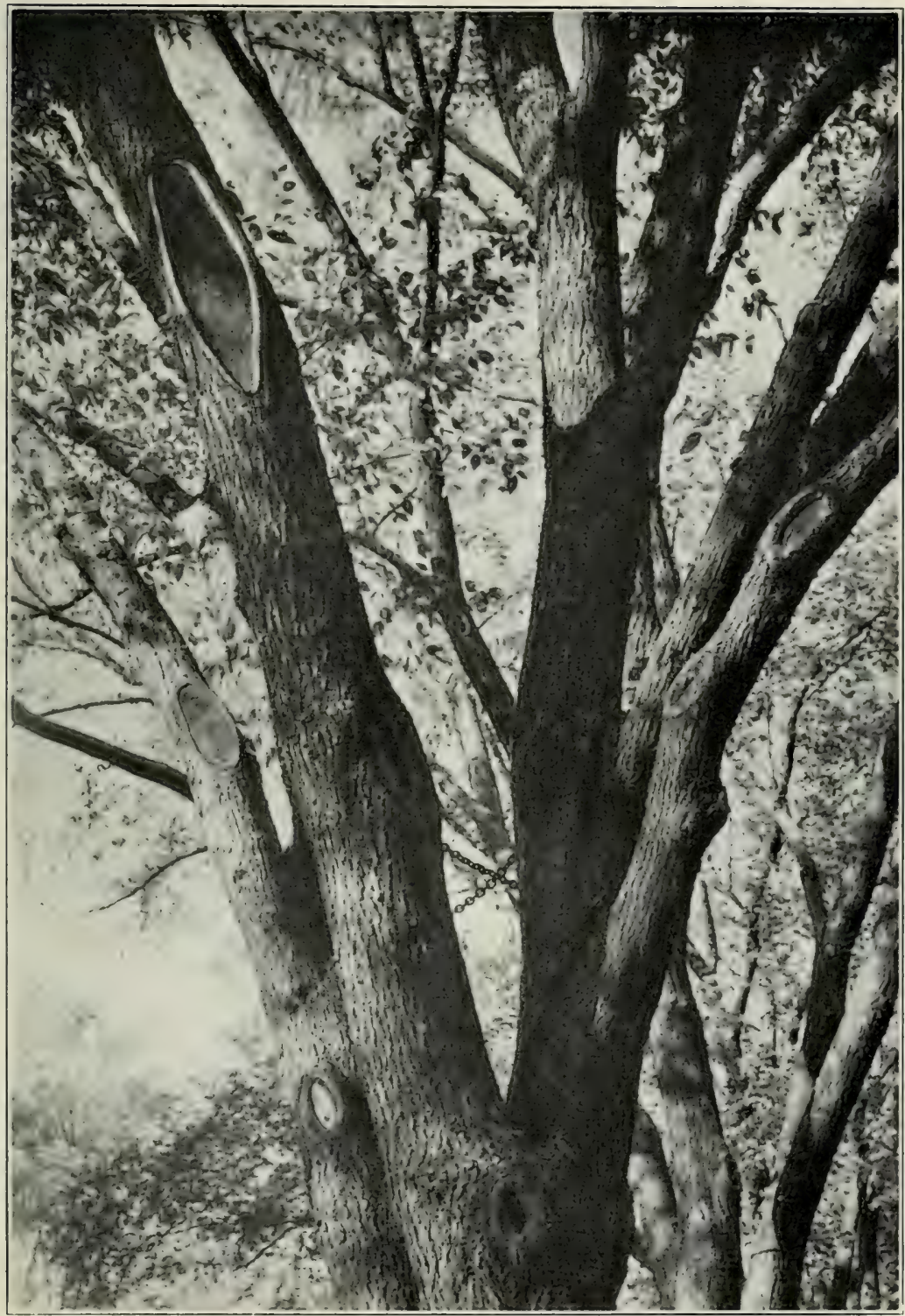

Fig. 4. Proper Pruning Insures Sound Trees. These cuts, made flush with the bark so no stubs remain, have been correctly covered with a waterproof coating and are growing over with no decay of the wood.

The first cut (a) should be made on the lower side of the limb at least a foot out from the tree and should be carried in until the weight of the limb begins to bind the saw. The second cut (b) 
should be made on the upper side about an inch farther out from the tree than the first cut and should continue until the limb breaks

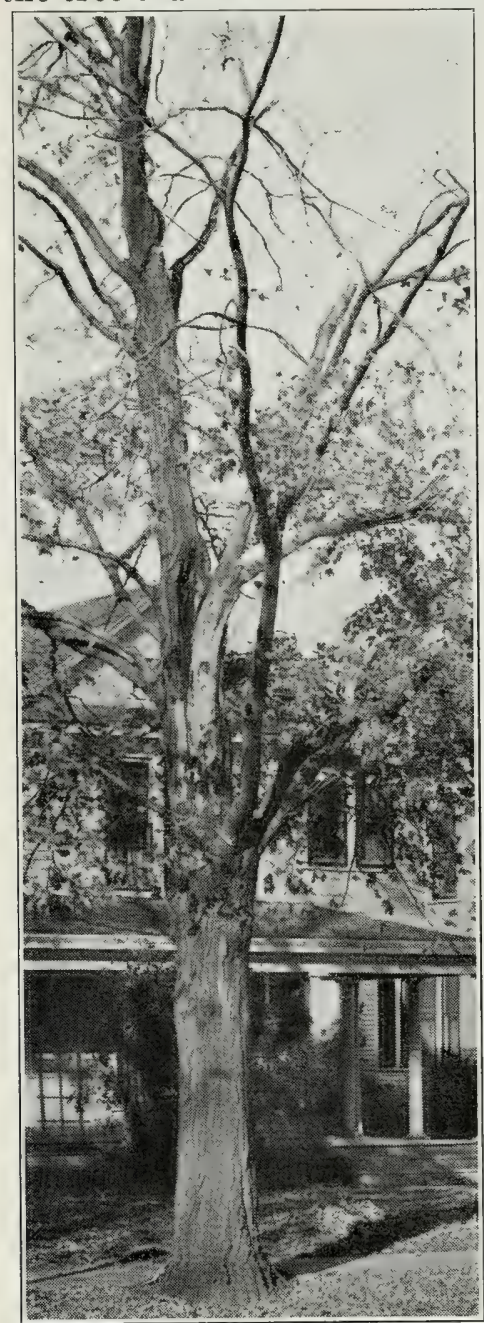

Fig. 5. A Neglected Tree. A limb broke off from this large hard maple during the winter of 1930. The injured places have not been cared for and in a few years decay will set in. off of its own weight. For the final cut (c) saw the stub off flush with the bark of the trunk or parent limb. This will make a larger wound than would be made by cutting the limb off farther out from the trunk, but it will be so shaped that healing will be much more rapid. Every limb removed should be cut so that no sign of a stub is left. This is just as important with small limbs as with large ones for a stub that does not heal properly, no matter how small, will decay back into the heart and cause the tree to become defective.

Painting the Wounds_Just as soon as cuts are made they should be painted to keep moisture and insects from gaining entrance. Many preparations have been used in the treatment of wounds, but none of them are superior to coal tar which does not become hard and brittle in ordinary temperatures. This tar may be secured from industrial plants manufacturing gas from coal, but should not be confused with water-gas tar that is obtained from the manufacture of gas from oil. Water-gas tar has almost no value as a preservative and should not be used. Wounds up to six inches in diameter may be given a heavy coating of coal tar as soon as they become dry but with larger wounds a coating of coal tar ereosote to within an inch of their edges should be applied. This should be allowed to dry and the whole wound then given a coating of the tar. On very large wounds several coats of tar may be necessary to give a lasting protective covering. Checking of the surface exposed in removing limbs will continue for several years and it is necessary to repaint these areas to maintain a waterproof surface. Large wounds should receive one or two coats the first 
year and every two or three years thereafter until they are completely healed over.

\section{SURGERY}

Tree surgery is no longer experimental; definite results have been obtained by certain practices and it is highly beneficial to trees in which decay has not progressed so far as to make the cost of the work excessive. In a broad sense of the word tree surgery consists of removing the diseased and decayed wood from a wound. A filling may or may not be put in depending entirely upon the size and shape of the cavity. Other than the mechanical support it gives to the tree a filling has very little or no value, for if a cavity properly cleaned will drain and is not large enough to weaken the tree, there is no necessity of going to the expense of putting in a filling.

In cleaning out a cavity the first step should be to remove all the rotten and diseased wood both above and below the opening. This may be done by using an outside ground gouge and a heavy wooden mawl. All unsound or discolored wood should be taken out and the inside of the eavity to within an inch of the bark given a good coat of coal tar creosote to kill any fungus that remains.

The opening of the eavity should be pointed or rounded at both top and bottom as the flow of sap is upward in the tree and healing will be entirely from the sides. If the cavity is too small to weaken the tree, shaping the bottom of it so that all water will drain out and coating the interior several times with coal tar is all that is necessary. If it is large enough to weaken the tree it should be filled either with a mixture of concrete, one part cement to three parts sand, or with various asphalt compositions.

Unhealthy trees like unhealthy people should be given the attention of some competent person. Their care should not be entrusted to quack tree doctors who travel the country. These men often have marvelous inventions which according to their claims will, if placed in the hole bored in the tree or sprayed on its trunk, protect that tree from all diseases and insects. These claims are absolutely false for there is no known method of treating the diseases or insects which attack our shade trees other than by spraying or banding for insects and cutting away the infected area of a tree attacked by fungus. 


I

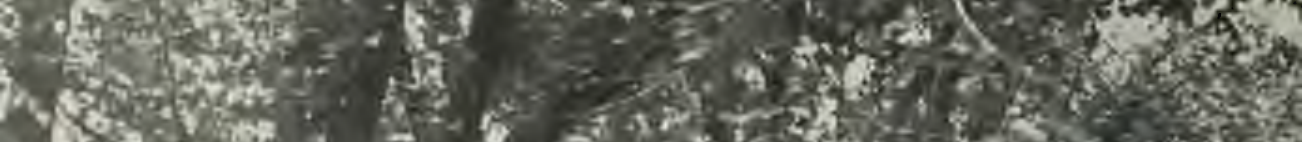

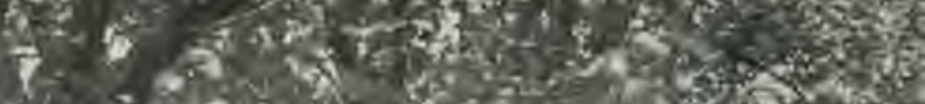

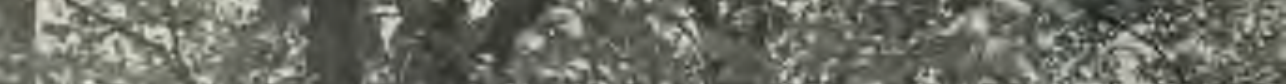
W

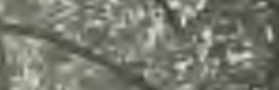

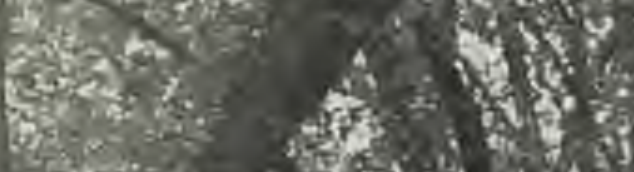

2. Al

2. Al x.

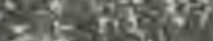

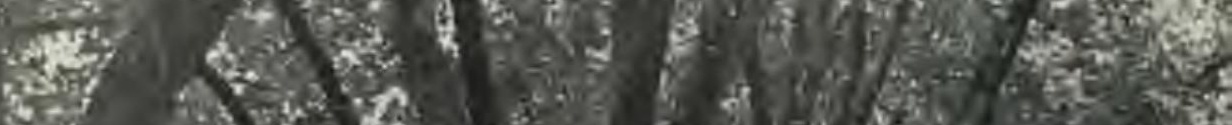

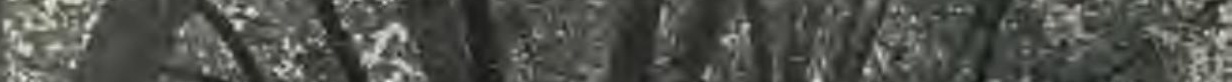

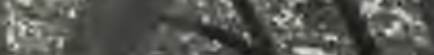

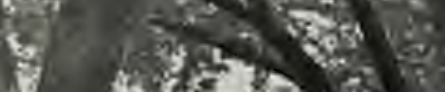

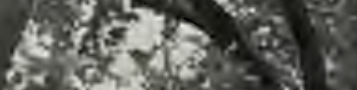
$x^{2}=13$

2.

it:

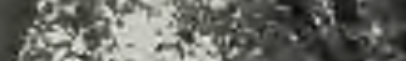

8.6.

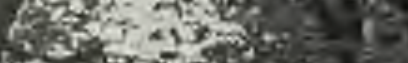

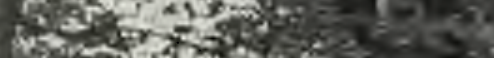

(a) 6.

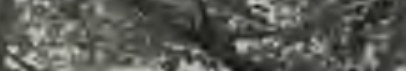

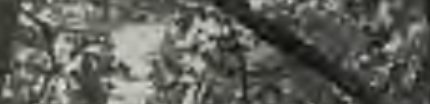

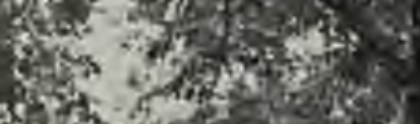

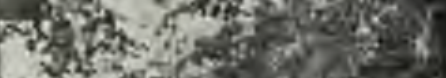

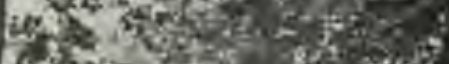

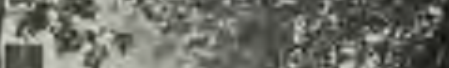

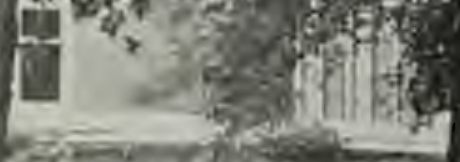

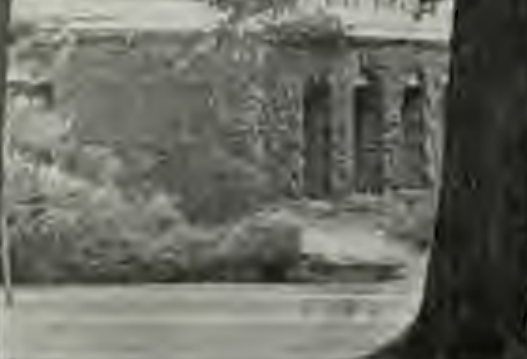

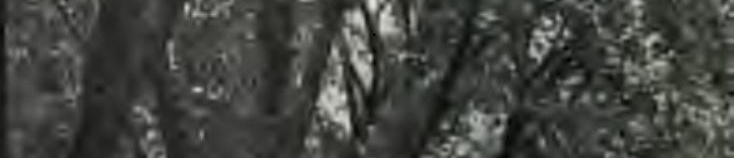

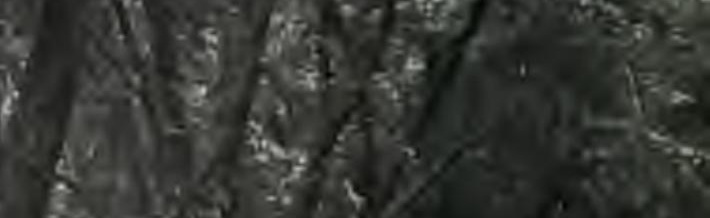

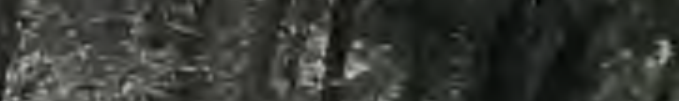

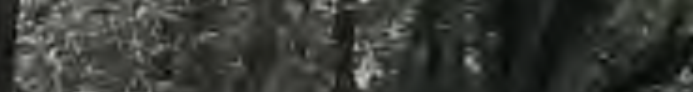

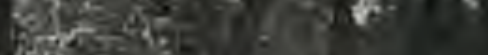
$x+2 y=28$ $=$

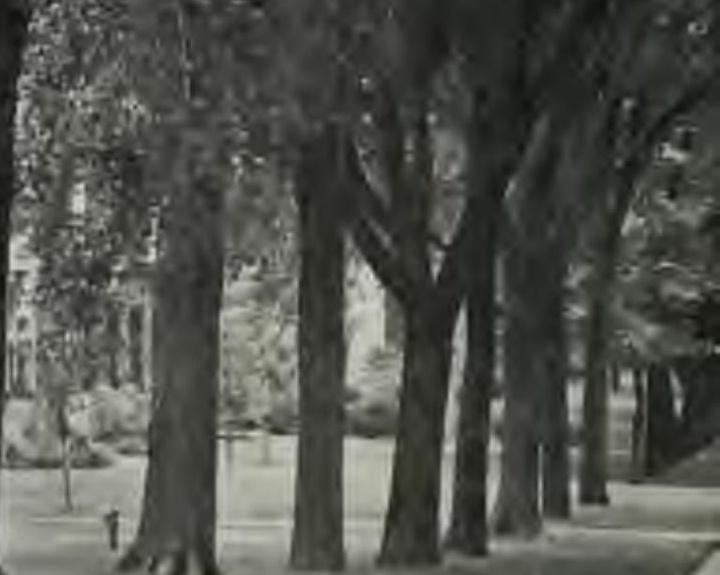






UNIVERSITY OF ILLINOIS-URBANA

570IL6C

CIRCULAR

C006

1-24

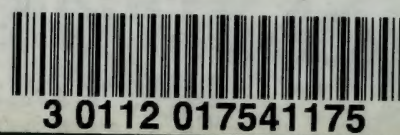

